\title{
Influence of breast cancer subtype on pathological complete response
}

\author{
Bruno de Carvalho Mancinelli1* (1), Marcelo Antonini ${ }^{10}$,

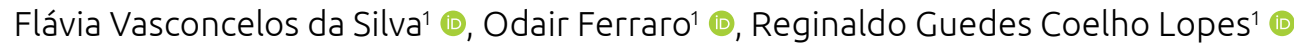

\section{ABSTRACT}

Objective: To compare the rates of pathological complete response ( $\mathrm{PCR}$ ) after treatment with neoadjuvant chemotherapy, in the different subtypes of breast cancer in patients followed at the Mastology Service of Hospital do Servidor Público Estadual. Methods: Descriptive and retrospective study, in which medical records of 213 patients diagnosed with breast cancer and submitted to neoadjuvant chemotherapy were reviewed, from February 2011 through January 2018. Histological data collected were: hormone receptors, hyperexpression of HER-2, grade, histological type and clinical data: age of the patient at diagnosis, tumor size and clinical stage at diagnosis and after chemotherapy, and rate of pCR. Results: The mean age of patients at diagnosis was 53.97 years. Forty-six patients (21,6\%) had pCR, 77 (36.1\%) were grade 2 and 136 (63.9\%) were grade 3. Regarding cancer subtype, 29 patients (13.6\%) were reported to have pure HER2 subtype, 48 patients (22.5\%) corresponded to Luminal A subtype, 51 (23.9\%) to Luminal B, and 66 patients (31.0\%) were characterized as Triple Negative, while only 17 patients (7.9\%) had Luminal B HER. Conclusion: The subtypes Pure HER 2 and Luminal B had the highest pCR rates.

KEYWORDS: breast cancer; combined modality therapy; chemotherapy.

\section{INTRODUCTION}

Breast cancer is the most common type of cancer among women in the world and, in Brazil, is behind non-melanoma skin cancer, accounting for $28 \%$ of new cases each year. The National Cancer Institute estimates 66,280 new cases of breast cancer in Brazil for every 100 thousand inhabitants in $2020^{1}$.

All systemic therapies applied to non-metastatic breast cancer is intended to reduce the risk of distant recurrence. In addition, the objective its administration before surgery is to shrink the tumor, which may allow for less extensive surgery on the breast and/or armpit, increased conservative surgery instead of mastectomy, improved aesthetic results and reduced postoperative complications, such as lymphedema ${ }^{1,2}$. Neoadjuvant therapy also allows an early assessment of the effectiveness of systemic therapy. In addition, the presence or absence of residual invasive cancer after neoadjuvant chemotherapy (NACT) is a strong prognostic factor for the risk of recurrence, especially in triple negative breast cancer (TNBC) and positive human epidermal growth factor receptor 2 (HER2) $)^{3-6}$.
Although there is no consensus in the literature on what to consider a pathological complete response (pCR), we can define it as the absence of cancer (invasive or in situ) in both the breast and the armpit, identifying morphological findings in breast tissue that are consistent with regression of the neoplasia and define a possible tumor bed upon anatomopathological assessment ${ }^{7}$.

Breast cancer patients who present with pCR after NACT have a better prognosis when compared to those who have incomplete responses. The NSABP B-18 and NSABP B-27 studies compared NACT with adjuvant chemotherapy using Adriamycin with cyclophosphamide (CA) in isolation or associated with taxanes, and reported better disease-free survival (DFS) and overall survival (OS) in patients with pCR; however, the pCR rates were $13 \%$ and $26 \%$, respectively. The final analysis failed to show which subgroups would benefit most from NACT to improve DFS and OS, and also did not show reduction in mortality ${ }^{8,9}$.

Different molecular subtypes respond differently, with TNBC and breast cancer with HER2 overexpression responding better than luminal subtypes. Immunotherapies, such as trastuzumab,

Hospital do Servidor Público Estadual, Instituto de Assistência Médica ao Servidor Público Estadual de São Paulo - São Paulo (SP), Brazil.

*Corresponding author: brunomancinelli@gmail.com

Conflict of interests: nothing to declare.

Received on: 02/18/2020. Accepted on: 06/02/2020. 
and chemotherapeutic agents, such as anthracyclines and taxanes, are used in the search for better results in primary treatment of breast cancer ${ }^{10-12}$.

Given the importance of the topic, this study aims to compare the rates of pCR after NACT in different subtypes of breast cancer in patients followed at the Mastology outpatient clinic of a public hospital.

\section{METHODS}

\section{Type of study and ethical aspect}

This is a retrospective descriptive study comprising female patients followed up at the Mastology outpatient clinic of Hospital do Servidor Público Estadual - Francisco Morato de Oliveira (HSPE-FMO), between February 2011 and January 2018, with confirmed diagnosis of cancer and submitted to NACT. The project was approved by the Ethics and Research Committee and registered in "Plataforma Brasil" (Certificate of Presentation for Ethical Consideration-CAAE: 86418618.0.0000.5463).

\section{Study design and ethical aspect}

Clinical and laboratory data of patients from medical records were reviewed: age, tumor size at diagnosis, clinical and pathological stage (TNM staging), hormone receptors (HR), HER2 overexpression, Ki-67proliferation index, tumor grade and histological type at biopsy, and pCR. HR and HER2 overexpression were analyzed by quantitative immunohistochemistry (IHC). HER2 overexpression was considered positive only when the result on IHC was 3+ or with a positive Fluorescence In Situ Hybridization (FISH) test.

The Ki-67 proliferation index was used to differentiate the luminal subtypes and the value of $14 \%$ was considered as cutoff, that is, patients who presented only positive hormone receptors with Ki-67 below 14\% were classified as Luminal A and above $14 \%$, as Luminal B. The triple negative subtype (TNBC) was considered when estrogen receptors (ER), progesterone receptors (PR) and HER2 were all negative. Luminal B - HER2 (LB-HER) was defined when ER or PR were positive with high Ki-67 and HER2 overexpression. Finally, subtype pure HER2 (pure HER) was defined upon negative ER and PR and positive HER2.

All patients included in the analysis were properly screened with computed tomography of the chest and abdomen, and submitted to bone scintigraphy in order to exclude metastatic disease.

Patients submitted to NACT for inflammatory carcinoma were not included in the sample.

The sequence and schema of chemotherapy drugs were defined by the institution's attending physician, without central standardization. The main antineoplastic agents used were: adriamycin, cyclophosphamide, docetaxel and trastuzumab, the latter only in patients with HER2 overexpression.
In patients receiving trastuzumab as neoadjuvant therapy, the drug was maintained for 18 cycles. For these patients, transthoracic echocardiography was performed to assess cardiac function every 12 weeks.

In this study, absence of invasive or in situ residual tumor in the breast and armpit was considered as $\mathrm{pCR}^{7}$.

Ten patients were excluded from the sample: seven did not have a sequential NACT scheme and three died, which results in medical records not being released for analysis.

An informed consent form was not required, as the paper resulted from medical records' review and patients did not have their identity revealed.

\section{Statistical analysis}

The $\chi^{2}$ test was used to analyze the association between pCR and the independent variables, as well as pCR rates in different types of tumor. To assess the epidemiological profile of patients with different histological types, univariate analysis was applied.

The simple logistic regression model was applied to assess odds ratio between the dependent variable pCR and independent variables. Multidimensional data were analyzed using the multiple correspondence factor analysis technique in order to assess associations. Statistical analysis was performed on the software R 3.4.2, with significance level set at below $5 \%$.

\section{RESULTS}

The sample had 213 patients who underwent chemotherapy and were evaluated. The mean age was $54 \pm 9$ years, with age range between 29 and 72 years (median of 54 years).

The pCR was present in $22.6 \%(n=46)$, while $36.1 \%(n=77)$ presented stage II and $63.9 \%(\mathrm{n}=136)$ stage III. As for the histological grade of tumors, $9.3 \%(n=20)$ of patients had grade I, $53 \%(n=113)$ grade II and $37.7 \%(n=80)$ grade III. As for cancer subtype, $22.5 \%$ of patients had Luminal A subtype, 23.9\% Luminal B, 7.9\% LB-HER, 31\% TNBC and 13.6\% pure HER subtype.

Conservative surgery was possible in $59 \%$ of cases. However, axillary emptying was necessary in $89.3 \%$ of cases (Table 1).

When checking pCR in molecular subtypes, responses varied between 10 and $41 \%$, with the worst responses for Luminal $A$ and $B$ and tumors with HER2 overexpression with a higher prevalence of $\mathrm{pCR}$.

The analysis of subgroups identified an association of the pCR in patients with pure HER and LB-HER with the histological grade (Table 2).

Table 2 shows that the highest $\mathrm{pCR}$ rates were found in grade II and III tumors, those with negative HR and positive HER. The only subtype that did not follow this trend was Luminal A. 


\section{DISCUSSION}

In this study, 46 patients (22.6\%) reached a pCR, but this was less frequent in subtypes LA and LB: $10.4 \%$ and $11.8 \%$, respectively. In TNBC, pCR was reached in $24.2 \%$ of cases. In patients with HER2 overexpression, $p C R$ was observed in $41.2 \%$ of LB-HER cases and $37.9 \%$ in patients without HR expression. Similar results were found by Monteiro et al. ${ }^{13}$, which suggests that the tumor response to NACT is not affected by systemic comorbidities, but rather influenced negatively by HR expression.

Despite the subtype LA being the most prevalent breast tumor in the literature $e^{4-7}$, in this study its prevalence was lower than other subtypes (for example, TNBC). As it presents a good response to adjuvant hormonal treatment ${ }^{9}$, its first treatment is surgery, especially when found in early stages.
In our sample, only 46 patients $(22.6 \%)$ reached a pCR, which corroborates the meta-analysis by Spring et al. ${ }^{7}$, with 18,000 patients reaching the $\mathrm{pCR}$ in $21.5 \%$ of cases.

Of the total number of patients evaluated, $63.1 \%$ were in stage 3 , similar to the studies that evaluated the indication of NACT in locally advanced stages, aiming at less aggressive surgical approaches ${ }^{14}$. In addition, 53\% had histological grade II, similar to what Lopes et al. ${ }^{15}$ and Aquino et al..$^{16}$ reported: $56.6 \%$ and $52.2 \%$, respectively. The lower percentage of grade I $(9.3 \%)$ can be explained by the higher incidence of positive TN and HER2 subtypes, which, in general, are more prone to higher histological grades (II and III).

Of 213 patients evaluated, conservative surgery was possible in $59.0 \%$ of the cases, which corroborates data from the literature, in which NACT has become an alternative to expand the

Table 1. Characteristics of patients in relation to the presence or absence of pathological complete response (pCR).

\begin{tabular}{|c|c|c|c|c|}
\hline & No pCR & PCR & OR $(95 \% \mathrm{Cl})$ & p-value \\
\hline Receptor & n (\%) & n (\%) & & \multirow{5}{*}{0.035} \\
\hline ER and PR+ & $81(48.5)$ & $16(34.8)$ & 1 & \\
\hline ER+ & $13(7.8)$ & $0(0.0)$ & 1.19 (0.00-inf) & \\
\hline $\mathrm{PR}+$ & $6(3.6)$ & $3(6.5)$ & $2.53(0.57-11.17)$ & \\
\hline ER and PR - & $67(40.1)$ & $27(58.7)$ & $2.04(1.01-4.10)$ & \\
\hline Tumor type & n (\%) & n (\%) & & \multirow{6}{*}{0.004} \\
\hline LA & $43(25.9)$ & $5(11.1)$ & $0.19(0.06-0.63)$ & \\
\hline LB & $45(27.1)$ & $6(13.3)$ & $0.22(0.07-0.68)$ & \\
\hline LB-HER & $10(6.0)$ & $7(15.6)$ & $1.15(0.34-3.89)$ & \\
\hline Pure HER & $18(10.8)$ & $11(24.4)$ & 1.00 & \\
\hline TNBC & $50(30.1)$ & $16(35.6)$ & $0.52(0.2-1.34)$ & \\
\hline Nuclear grade & n (\%) & n (\%) & & \multirow{4}{*}{0.342} \\
\hline 1 & $18(10.8)$ & $2(4.3)$ & 1.00 & \\
\hline II & $89(53.3)$ & $24(52.2)$ & $2.43(0.53-11.19)$ & \\
\hline II & $60(35.9)$ & $20(43.5)$ & $3.00(0.64-14.08)$ & \\
\hline
\end{tabular}

OR: odds ratio; 95\%Cl: 95\% confidence interval; ER: estrogen receptor; PR: progesterone receptor; + positive; - negative; LA: luminal A; LB: luminal B; LB-HER: luminal B - HER2; Pure HER: pure HER2; TNBC: triple negative breast cancer.

Table 2. Characteristics of the subtypes in relation to the pathological complete response (pCR) and nuclear grade.

\begin{tabular}{|c|c|c|c|c|c|c|}
\hline & Pure HER & LA & LB & LB-HER & TNBC & \multirow{2}{*}{ p-value } \\
\hline & n (\%) & n (\%) & n (\%) & n (\%) & n (\%) & \\
\hline$N$ & 29 & 48 & 51 & 17 & 66 & \\
\hline pCR & $11(37.9)$ & 5 (10.4) & $6(11.8)$ & $7(41.2)$ & $16(24.2)$ & 0.004 \\
\hline \multicolumn{7}{|c|}{ Grade (\%) } \\
\hline I & $0(0.0)$ & $10(20.8)$ & $5(9.8)$ & $1(5.9)$ & $4(6.1)$ & \multirow{3}{*}{$<0.001$} \\
\hline II & $14(48.3)$ & $32(66.7)$ & $32(62.7)$ & 9 (52.9) & 25 (37.9) & \\
\hline III & $15(51.7)$ & $6(12.5)$ & $14(27.5)$ & $7(41.2)$ & $37(56.1)$ & \\
\hline
\end{tabular}

Pure HER: pure HER2; LA: luminal A; LB: luminal B; LB-HER: luminal B - HER2; TNBC: triple negative breast cancer. 
indication of conservative surgery in patients who, initially, are not candidates for the procedure. Axillary emptying was necessary in $89.3 \%$ of cases, similar results reported by Van Vaisberg et al. ${ }^{17}$, in which $85 \%$ of patients were submitted to axillary emptying. Such data can be explained by the higher percentage of advanced stages and, in addition, during the sample collection period, axillary emptying was the choice in the case of clinically compromised armpits (N1+). Mamtani et al. ${ }^{6}$ and Donker et al. ${ }^{18}$ found that, with the increase in indications for sentinel lymph node biopsy in cases of clinical response in the axilla, axillary emptying rates were reduced by $60 \%$.

It is known that the NACT response is greater in tumors with negative ER, TN, positive HER2. We could observe that the pure HER2 (37.9\%) and luminal B HER (41.2\%) subtypes presented the highest pCR rates. Data reported by Boughey et al. ${ }^{19}$ and Silva et al. ${ }^{20}$ confirm similar values $(45.4 \%)$.

In our study, no dual anti-HER2 therapy was performed in a neoadjuvant environment. As per publication by Nitz et al. ${ }^{21}$, it is known that pCR rates for tumors with HER2 overexpression can reach up to $70 \%$.
In $\mathrm{TNBC}$, the rate of $24.2 \%$ of pCR was lower than that reported by Spring et al. ${ }^{7}$ in their meta-analysis; however, it should be noted that the lack of standardization of NACT schemes observed in this sample may have influenced the pCR rate verified in this study, bringing limitations to the comparison with current references.

Therefore, it should be noted that the limitations of this study stem from the lack of standardized schemes for NACT, which makes it difficult to compare pCR rates in different breast cancer subtypes. In addition, some of the drugs used in major world centers were not available at the hospital chosen for assessment, making the pCR rate of some subtypes (for example tumors with HER2 overexpression) lower than current data. Further studies are suggested, with the standardization of chemotherapy schemes and the use of new drugs already approved.

\section{CONCLUSION}

Although the pCR rate varies according to breast cancer subtype, pure HER2 and luminal B HER2 subtypes were the ones with the highest rates.

\section{REFERENCES}

1. Brasil. Ministério da Saúde. Tipos de câncer: câncer de mama [Internet]. Brasil: Instituto Nacional do Câncer [acessed on July 17,2017]. Available at: http://www2.inca.gov.br/wps/wcm/ connect/tiposdecancer/site/home/mama/cancer_mama

2. Bardia A, Baselga J. Neoadjuvant therapy as a platform for drug development and approval in breast cancer. Clin Cancer Res. 2013;19(23):6360-70. https://doi.org/10.1158/1078-0432. ccr-13-0916

3. Ueno NT, Buzdar AU, Singletary SE, Ames FC, McNeese MD, Holmes FA, et al. Combined-modality treatment of inflammatory breast carcinoma: Twenty years of experience at M.D. Anderson Cancer Center. Cancer Chemother Pharmacol. 1997;40(4):321-9. https://doi.org/10.1007/s002800050664

4. Pachnick JPA, Czeczko NG, Tuon F, Cavalcanti TS, Malafaia AB, Tuleski AM. Avaliação imunoistoquímica dos receptores de estrogênio e progesterona no câncer de mama, pré e pósquimioterapia neoadjuvante. Rev Col Bras Cir. 2012;39(2):8691. https://doi.org/10.1590/S0100-69912012000200002

5. Schwartz GF, Hortobagyi GN. Proceedings of the consensus conference on neoadjuvant chemotherapy in carcinoma of the breast, April 26-28, 2003, Philadelphia, Pennsylvania. Cancer. 2004;100(12):2512-32. https://doi.org/10.1002/cncr.20298

6. Mamtani A, Barrio AV, King TA, Van Zee KJ, Plitas G, Pilewskie $\mathrm{M}$, et al. How Often Does Neoadjuvant Chemotherapy Avoid Axillary Dissection in Patients With Histologically Confirmed Nodal Metastases? Results of a Prospective Study. Ann Surg Oncol. 2016;23(11):3467-74. https://dx.doi. org/10.1245\%2Fs10434-016-5246-8
7. Spring L, Greenup R, Niemierko A, Schapira L, Haddad $\mathrm{S}$, Jimenez $\mathrm{R}$, et al. Pathologic complete response after neoadjuvant chemotherapy and long-term outcomes among young women with breast cancer. J Natl Compr Cancer Netw. 2017;15(10):1216-23. https://doi.org/10.6004/jnccn.2017.0158

8. Rastogi P, Anderson SJ, Bear HD, Geyer CE, Kahlenberg MS, Robidoux A, et al. Preoperative chemotherapy: Updates of national surgical adjuvant breast and bowel project protocols B-18 and B-27. J Clin Oncol. 2008;26(5):778-85. https://doi. org/10.1200/jco.2007.15.0235

9. Gralow JR, Burstein HJ, Wood W, Hortobagyi GN, Gianni L, Von Minckwitz G, et al. Preoperative therapy in invasive breast cancer: Pathologic assessment and systemic therapy issues in operable disease. J Clin Oncol. 2008;26(5):814-9. https://doi. org/10.1200/jco.2007.15.3510

10. Cortazar P, Zhang L, Untch M, Mehta K, Costantino JP, Wolmark $\mathrm{N}$, et al. Pathological complete response and long-term clinical benefit in breast cancer: The CTNeoBC pooled analysis. Lancet. 2014;384(9938):164-72. https://doi. org/10.1016/s0140-6736(13)62422-8

11. Carey LA, Dees EC, Sawyer L, Gatti L, Moore DT, Collichio F, et al. The triple negative paradox: Primary tumor chemosensitivity of breast cancer subtypes. Clin Cancer Res. 2007;13(8):2329-34. https://doi.org/10.1158/1078-0432.ccr-06-1109

12. Precht LM, Lowe KA, Atwood M, Beatty JD. Neoadjuvant chemotherapy of breast cancer: Tumor markers as predictors of pathologic response, recurrence, and survival. Breast J. 2010;16(4):362-8. https://doi.org/10.1111/j.1524-4741.2010.00935.x 
13. MonteiroHdeAV,Goulart-CitranguloSMT,LeiteMS, Giacomin LC, Vianna-Jorge R. Influência de Variáveis Clinicopatológicas sobre a Eficácia da Quimioterapia Neoadjuvante do Câncer de Mama. Rev Bras Cancerol. 2013;59(3):369-77.

14. Santos TP, Paes MA, Ferreira ACS de M, Campos T. Avaliação epidemiológica das pacientes com câncer de mama tratadas com trastuzumabe no Hospital de Base de Brasília. Rev Bras Oncol Clínica. 2014;10(36):55-9.

15. Lopes LAF, Linhares, JJ, Ferraro O, Guedes R, Lopes C, Baracat FF. Valor prognóstico do grau histológico $(\mathrm{GH})$, grau nuclear (GN) e índice mitótico (IM) para pacientes com carcinoma da mama estádios II e III com linfonodos axilares comprometidos. Rev Bras Cancerol. 2006;52(3):245-51.

16. Aquino RGF de, Pinheiro LGP, Cavalcante DIM, Vasques PHD, Oliveira AL de S, Silva CAB da. Carcinoma ductal invasor: comparação dos graus histológicos entre tumor primário e metástase axilar. Rev Bras Mastol. 2016;26(2):45-9.

17. Van Vaisberg V, Vilas Boas MDS, Stephan BDO, Matutino ARB, Lima JMDS, Mano MS. Câncer de mama: efeito prognóstico da resposta patológica completa após quimioterapia neoadjuvante. Rev Med. 2015;94(Supl.):31. https://doi. org/10.11606/issn.1679-9836.v94isupl.p31-31
18. Donker M,van Tienhoven G, Straver ME, Meijnen P, van de Velde $\mathrm{CJH}$, Mansel RE, et al. Radiotherapy or surgery of the axilla after a positive sentinel node in breast cancer (EORTC 1098122023 AMAROS): A randomised, multicentre, open-label, phase 3 non-inferiority trial. Lancet Oncol. 2014;15(12):130310. http://dx.doi.org/10.1016/S1470-2045(14)70460-7

19. BougheyJC,SumanVJ,MittendorfEA,AhrendtGM,WilkeLG,Taback B,etal.Sentinellymphnodesurgeryafterneoadjuvantchemotherapy in patients with node-positive breast cancer: The ACOSOG Z1071 (alliance) clinical trial.J Am Med Assoc. 2013;310(14):1455-61.https:// dx.doi.org/10.1001\%2Fjama.2013.278932

20. Silva EHL de S, Paloschi JRA, Caldeira JR de F, Joioso A. Estudo comparativo de resposta à quimioterapia neoadjuvante em dose total, entre câncer de mama e metástase axilar, conforme resultados de imunoistoquímica, no Serviço de Mastologia do Hospital Amaral Carvalho em Jaú, SP. Rev Bras Mastol. 2015;25(2):46-50. https://dx.doi.org/10.5327/Z201500020003RBM

21. Nitz U, Gluz O, Christgen M, Grischke EM, Augustin D, Kümmel S, et al. Final analysis of WSG-ADAPT HER2+/HR-trial:Efficacy, safety, and predictive markers for 12-weeks of neoadjuvant dual blockade with trastuzumab + pertuzumab \pm weekly paclitaxel in HER2+/HR- early breast cancer (EBC).J Clin Oncol. 2016;34(15 Supl.):518. https://dx.doi.org/10.1200/JCO.2016.34.15_suppl.518 